\title{
Consideraciones conceptuales de incidencia económica y de estructura jurídica del impuesto sobre las ventas en Colombia, presupuestos de sujeción, no sujeción y exoneraciones*
}

\section{Conceptual considerations, of economic incidence and legal structure of the Value Added Tax in Colombia, the concepts of taxed, not taxed and exonerations}

\author{
EDICSON ALEJANDRo ORTIZ DICELIS ${ }^{1}$
}

\section{Resumen}

El presente artículo contempla las consideraciones del autor destacando las características de "pluricausación” del impuesto, método adoptado en Colombia para el Impuesto sobre las Ventas y conforme al cual se realiza un análisis desde su estructura jurídica y su aplicación en perspectiva económica. Al respecto, se pone de presente el concepto de materia imponible del impuesto, para considerar luego de manera conceptual los Supuestos de No Sujeción, Gravamen bajo Tarifas General y Diferencial, Exentos y Excluidos, a su vez, en relación con estos dos últimos conceptos, se contempla un análisis de la incidencia que genera en las cadenas económicas desde los conceptos de exoneración perfecta e imperfecta. Finalmente, se recogen estas consideraciones para destacar elementos de normativa y práctica frente a la incidencia y neutralidad en cadenas de

* DOI: https://doi.org/10.18601/16926722.n10.02

${ }^{1}$ Magíster en Derecho con énfasis en Tributación de la Universidad Externado de Colombia. Especialista en Finanzas Públicas de la Escuela Superior de Administración Pública-ESAP- donde obtuvo distinción de matrícula de honor por desempeño académico. Especialización en Curso en Docencia Universitaria de la UCC. Diplomado en Administración Tributaria del Centro Interamericano de Administraciones Tributarias - CIAT- y en Contabilidad Internacional -IFRS- de la Universidad Nacional de Colombia. Contador Público titulado. Ha sido miembro de la multinacional de auditoria KPMG y del Fondo de Empleados de las Instituciones Colombianas Agropecuarias -CORVEICA-, actualmente hace parte de la Dirección de Impuestos y Aduanas Nacionales -DIANen la División de Fiscalización para Personas Jurídicas y Asimiladas de la Seccional de Impuestos de Bogotá. Correo electrónico: edicson.ortiz@est.uexternado.edu.co 
producción, inversión y consumo, destacando para su conceptualización la relación existente de servicios a bienes en dirección del consumo de bienes.

Palabras clave: Impuesto al Valor Agregado (IVA), incidencia tributaria, neutralidad, cadena de producción, inversión, consumo, Exoneración, Exoneración perfecta, Exoneración Imperfecta, Excluido, Objeto imponible.

\section{Abstract}

The present article addresses some considerations of the author, emphasizing the features of "pluricausación" of the sales tax, method adopted in Colombia for the Value Added Tax according to which it is performed an analysis from its legal structure and its application from the economic perspective. It mentions the concept of taxable base, to consider afterwards concepts, not taxed, taxed at general and differential rates, exemption and exclusion, the relationship between these two last concepts, it also analyses the incidence in the economic chains from them concepts of perfect and imperfect exemption. Finally, these considerations are included to point out elements of legislation and practice facing the incidence and neutrality in chains of production, investment and consumption, mainly the relationship of services to goods in the direction of the consumption of goods.

Key words: Value Added Tax (VAT), incidence tax, neutrality, chains of production, investment, consumption, exemption, perfect exemption, imperfect exemption, excluded, taxable object.

\section{Sumario}

Introducción. I. Consideraciones frente a la estructura del impuesto sobre las ventas en la modalidad de valor agregado. A. Impuesto sobre las ventas y los impuestos al consumo: su estructura en función de la Materia Imponible. II. Consideraciones conceptuales en relación con los supuestos de no sujeción, gravamen en tarifas general y diferencial, exentos y excluidos (exoneraciones - perfecta e imperfecta). III. Consideraciones económicas de los presupuestos de exención y exclusión, su incidencia en las cadenas económicas y los precios. A. La exoneración perfecta, bienes y servicios exentos - el régimen de tasa cero. B. La exoneración imperfecta, bienes y servicios excluidos. IV. Consideraciones de la incidencia económica en cadena de la relación de servicios a bienes en dirección del consumo de bienes. Referencias.

\section{Tabla de abreviaturas}

IVA Impuesto sobre valor agregado

CAN Comunidad Andina de Naciones

\section{Introducción}

El objeto del presente artículo es analizar el régimen del impuesto sobre las ventas a partir de los supuestos de sujeción, no sujeción y de desgravación perfecta e imperfecta en el régimen del impuesto sobre las ventas, pasando por su consideración dogmática y conceptual, su estructura jurídica en Colombia y su aplicación práctica. De tal manera, analizar la relación de cadena económica del IVA, articulando los elementos que conforman su materia imponible como son los bienes y servicios. Para finalmente, mostrar el comportamiento de influencia en factores 
económicos como: los precios, la producción, la inversión y el consumo.

\section{Consideraciones frente a la estructura del impuesto sobre las ventas en la modalidad de valor agregado}

\section{A. Impuesto sobre las ventas y los impuestos al consumo: su estructura en función de la materia imponible}

En razón a su estructura, cabe recordar que el IVA en Colombia responde a la modalidad de valor agregado, lo que supone una cadena económica, es decir, varias etapas, cadena en la cual en cada uno de sus eslabones se genera un valor agregado respecto de la que le precede y en dicho valor recae el gravamen. Para ello, se distinguen principalmente tres métodos: la adición en la base, la sustracción en la base y el crédito de impuesto contra impuesto, en relación con los dos primeros la depuración se efectúa sobre la base del impuesto, mientras que en el tercero, aplicable en Colombia, se efectúa sobre el impuesto propiamente dicho y consiste en sustraer del impuesto generado sobre las ventas, el impuesto pagado a proveedores por las compras de insumos, productos terminados y servicios.

Sin perder de vista lo anterior, se debe atender de igual manera en su concepción natural que el impuesto sobre las ventas desde el punto de vista de la clasificación económica de los impuestos y del objeto imponible de la renta, según el momento económico en que se grava, se considera un impuesto al consumo en la medida que afecta la renta gastada, de la que se deriva, de igual manera, su denominación de impuesto al gasto y, por tal razón, grava de manera objetiva bienes o servicios sin consultar distinción alguna del sujeto del impuesto, por lo menos en principio y por regla general.

\section{Figura 1.}

\begin{tabular}{|l|l|l|}
\hline \multicolumn{1}{|c|}{ Modalidades } & \multicolumn{2}{|c|}{ Métodos } \\
\hline Monofásico & 1. Aplicable en primera etapa \\
\hline & 2. Aplicable en etapa intermedia \\
\hline & 3. Aplicable en última etapa \\
\hline Plurifásico & \multicolumn{1}{|l|}{ Acumulativo o en cascada: pleno sobre la venta } \\
\hline & Tipo valor agregado & 1. Adición en la base \\
\hline & & 2. Sustracción en la base \\
\hline & & 3. Crédito de impuestos contra impuesto \\
\hline
\end{tabular}

Fuente: elaboración propia, 2015. A partir de Plazas Vega (2015, p. 41).

En relación con su incidencia económica, cabe destacar que en principio el impuesto en modalidad de valor agregado bajo el método de impuesto contra impuesto supone neutralidad económica para los eslabones de la cadena, pues si bien cada uno de los intervinientes en cada etapa debe entregar al Estado un valor liquidado por IVA. Este valor no es propiamente un recurso sufra- gado por ellos (los eslabones de la cadena), sino que es incidido en el consumidor final vía precio, y es allí donde se materializa el consumo como manifestación de capacidad contributiva. A pesar de ello, en el sistema colombiano se han incorporado elementos que, como será detallado más adelante, generan distorsiones en los precios, tales como la exoneración imperfecta o exclusión, así 
como factores de exoneración en función de la destinación o del sujeto.

Por otra parte, la anotada característica de incidencia en consumidor final, también imprime la crítica más importante que se realiza sobre el IVA, y es el no consultar las características del sujeto incidido, por tal un impuesto con un sesgo regresivo, y en esa medida es que el axioma de Consumo= Ingreso - Ahorro encuentra mayor afectación en las personas con más bajos recursos, por cuanto estas personas dispondrán de mayor parte de su renta para suplir el impacto del impuesto repercutido, lo cual impone al sistema adoptar mecanismos que incorporen elementos más progresivos, como exenciones, tarifas diferenciales y devoluciones, entre otros, aun cuando esto pueda reducir la eficiencia administrativa (Piza, 2015, p. 33).

A su vez, en relación con su estructura jurídica y desde la obligación que impone el Estado, en consideración del deber de todo ciudadano de contribuir con los gastos e inversiones de este $^{2}$, es materia regulada en el libro III del Estatuto Tributario Nacional, el régimen del impuesto sobre las ventas a partir del cual se contiene la delimitación del hecho generador del impuesto conforme a los aspectos específicos de los elementos objetivo y subjetivo del gravamen, tales como los aspectos material, espacial, temporal y cuantitativo, así como lo consecuente con los sujetos pasivos del impuesto.

Así las cosas, el impuesto sobre las ventas en Colombia se constituye en un gravamen plurifásico bajo la modalidad de valor agregado o en cadena, aplicado bajo el método de impuesto contra impuesto, el cual se concentra en gravar el consumo, considerado como la manifestación de capacidad contributiva de la renta en el gasto, lo que impone grandes retos en su concepción jurídica, en la medida que guarda una importante característica de regresividad y posible incidencia económica, sobre todo en los sujetos de menores recursos, si no se acotan de manera adecuada sus elementos de imposición.

\section{Consideraciones conceptuales en relación con los supuestos de no sujeción, gravamen en tarifas general y diferencial, exentos y excluidos (exoneraciones - perfecta e imperfecta)}

Como ha sido señalado, el impuesto sobre las ventas tiene por elemento objetivo en el aspecto material el consumo, en tal virtud, el IVA tiene preponderancia por hechos gravados, particularmente en Colombia los bienes, los servicios, las importaciones y los juegos de suerte y $\operatorname{azar}^{3}$ y, por ello, las consideraciones de los sujetos que realizan tales hechos son pocas o casi ninguna (Piza, 2015, p. 42); es decir, un impuesto naturalmente indirecto, y si bien en nuestra legislación se han incorporado elementos eventualmente por necesidades sociales o políticas de gobierno, que observan las características del sujeto, estas medidas no desvirtúan ni cambian la naturaleza del impuesto.

En tal sentido, se quiere, desde ya y con el fin de ser claro en la relevancia para el IVA, destacar que las consideraciones sobre los sujetos no son la regla, sino que para nuestra legislación han respondido a decisiones excepcionales de necesidades internas, pero no naturales al sistema del impuesto, de lo contrario se tornaría en un gravamen

\footnotetext{
${ }^{2}$ Núm. 9 del art. 95 de la Constitución Nacional de Colombia.

${ }^{3} \mathrm{Al}$ respecto artículo 420 del Estatuto Tributario Nacional.
} 
personal y casi directo, desconociendo con ello que quienes pagan el tributo no son los reales contribuyentes, sino simplemente responsables ante el Estado, encargados de intermediar entre el sujeto que manifiesta su capacidad contributiva y el acreedor del tributo.

Cabe reiterar, siguiendo a Plazas (2015, p. 377), en relación con el sistema del impuesto sobre las ventas, que se explica en la modalidad de pluricausación en función del valor agregado por cada agente económico. En virtud del cual, el Estado percibe de cada responsable una suma a título de impuestos que equivale a la aplicación de la tarifa sobre su valor agregado y el vendedor repercute en su comprador el impuesto sobre el valor agregado acumulado. Hecha esta importante anotación, es pertinente así poner de presente que el impuesto sobre el valor agregado en Colombia presenta a su vez hechos de sujeción, no sujeción y desgravación, como se explicará en seguida.

En relación con los hechos de sujeción es claro que responde a la delimitación del hecho generador que realiza el legislador y que persigue básicamente, establecer los hechos facticos sobre los cuales recae el impuesto, complementado esto por el aspecto cuantitativo. Para el caso colombiano, se encuentra que pueden existir hechos gravados a una tarifa general o diferencial, en este último caso si corresponde a hechos taxativamente señalados en la ley para ser gravados a un $5 \%{ }^{4}$.

Por su parte, en relación con los supuestos de no sujeción, cabe traer a colación las consideraciones expuestas por el profesor
Gabriel Muñoz Martínez de acuerdo con dicho concepto, como los hechos o actos que no recaen dentro del ámbito de la definición normativa del hecho generador, de manera que la obligación tributaria no se causa porque no se realiza plenamente el hecho generador (Piza, 2013, p. 103), como, a su vez, es de resaltar que son distintos de los supuestos de desgravación como es la exención.

Así las cosas, los hechos de no sujeción son aquellos actos que no son considerados por la definición misma del hecho generador $\mathrm{y}$, por tanto, no causan el gravamen, como en Colombia, por ejemplo, sucedía, hasta la entrada en vigencia de la Ley 1819 de 2016, con las ventas de bienes inmuebles, en tanto que la ley solo había contemplado la causación en la venta de bienes muebles, o es el caso de los servicios que se prestan en una relación laboral o reglamentaria, pues en la definición misma de servicios para efectos del IVA, estos fueron dejados al margen de la consideración del hecho imponible.

Ahora bien, en relación con los supuestos de desgravación, es de consideración para el caso de Colombia atender a las dos denominaciones que toman las exenciones, o también llamadas exoneraciones, como son la exención y la exclusión, las cuales infortunadamente en algunas ocasiones conceptualmente suelen confundirse. Sobre las exclusiones es importante recordar que fue un sistema incorporado en nuestra legislación mediante la Ley 50 de 1984, en línea de eliminar las exenciones establecidas bajo las reformas del impuesto en $1974^{[5]}$.

Para su distinción, la de exento y la de excluido, se debe atender nuevamente a que

\footnotetext{
${ }^{4}$ Artículos 468-1 y 468-3 del Estatuto Tributario Nacional.

${ }^{5}$ Decreto Legislativo 2821 de 1974 , originado principalmente a partir de las consideraciones y propuestas realizadas por la denominada "Comisión Musgrave".
} 
el impuesto sobre el valor agregado es un impuesto indirecto y, a la vez, objetivo en relación con los hechos y actos sujetos del gravamen, sin considerar en poco o en nada los deudores del tributo, pues ellos son apenas eslabones de la cadena de producción y distribución y el verdadero contribuyente es quien materializa el consumo. Si bien ambas son exoneraciones, es decir, ambas responden en principio a hechos que realizan plenamente el hecho generador, la llamada exención de un bien o un servicio en el IVA considera una exoneración perfecta en función de la cual, el efecto económico del impuesto debe ser neutro para el responsable, porque aun cuando el bien se encuentre gravado, la calificación de exento incorpora como consecuencia jurídica para el responsable la posibilidad de no generar valor de impuesto y, además, descontar los IVA que le precedieron en el circuito económico al producto. Por tal, en este caso, el responsable entrega un bien o servicio libre del impuesto, es decir, se logra la exoneración del bien o del servicio en el consumo (objeto del gravamen), pero a su vez para no incorporar una afectación económica al eslabón de la cadena, el Estado le devolverá al responsable los impuestos pagados a sus proveedores.

Por su parte, la exclusión se configura como una exoneración imperfecta, la cual se incorpora en el sistema del impuesto sobre las ventas como una delimitación negativa del hecho generador del impuesto. Esto significa que, si bien se cumplen los presupuestos del hecho generador del tributo, el legislador señala en forma taxativa la no causación del impuesto sobre un determinado bien o servicio. De tal manera, al no causarse el impuesto no se dará paso tampoco al aspecto cuantitativo del tributo, es decir, no habrá base gravable ni tarifa alguna.

Sin embargo, de allí se denota su calificativo de exoneración imperfecta, pues si bien sobre el bien o el servicio de manera aparente no se incorporará valor por impuesto al consumidor final, lo cierto es que, para el agente económico que interviene en este eslabón de la cadena como vendedor, habrá incidencia económica, en la medida que por estar presuntamente al margen del sistema del tributo, no liquidará impuesto y no tendrá derecho a descuento. No obstante, este agente económico no responsable que ha intervenido en la cadena, verdaderamente se ha hecho parte del impuesto, pues inciden sobre él económicamente los valores pagados de IVA a proveedores en los eslabones precedentes del proceso, aunque con ello no logra obtener el derecho al descuento sobre el posible impuesto que generaría su valor agregado. En tal consideración, el agente económico en este caso termina por asumir los impuestos precedentes como parte del costo de producir el bien o el servicio y termina por trasladarlo al consumidor final vía precio, atendiendo en últimas que la incidencia de la estructura del IVA se encuentra en función del consumo.

En virtud de la estructura jurídica y los supuestos de sujeción no sujeción y exoneraciones, se pasa a ilustrar: 


\section{Figura 2. Relación de los supuestos de "sujeción”, “no sujeción” y "exoneración”}

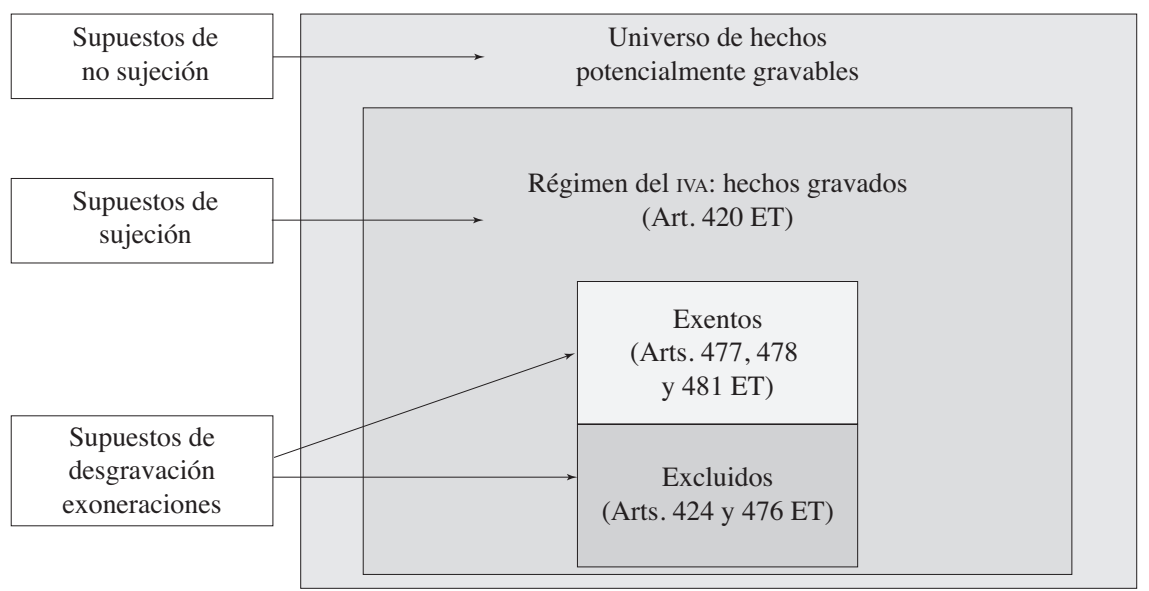

Fuente: elaboración propia, 2015.

De lo expuesto, se puede concluir que para efectos del IVA en Colombia se debe considerar que existen en el régimen unos supuestos de sujeción, es decir, unos hechos (ventas, servicios, importaciones, juegos de suerte y azar) ${ }^{6}$ que se gravan de manera objetiva ya sea a la tarifa general o a tarifa diferencial; a su vez que se desprenden unos supuestos de no sujeción, los cuales son hechos que quedan al margen del régimen del impuesto por no realizar plenamente el hecho generador (no gravados) y, finalmente, unas exoneraciones que tienen por resultado no materializar el efecto principal de la obligación tributaria (pagar el tributo) estableciendo supuestos de desgravación, como son: la exención, la cual guarda las características de una exoneración perfecta con un esperado efecto económico neutro en los bienes o servicios, y la exclusión, una calidad incorporada como exoneración imperfecta que tiene características infortunadas de incidencia económica en los precios.
Para ambos casos se procederá en seguida a ahondar en sus efectos.

\section{Consideraciones económicas de los presupuestos de exención y exclusión, su incidencia en las cadenas económicas y los precios}

Ha sido comentado que los supuestos de desgravación en el régimen de IVA en Colombia, se conciben como aquellos hechos que, realizando plenamente los presupuestos del hecho generador, son exonerados de manera taxativa por el legislador, ya sea esto por políticas de gobierno, incentivo a su producción, protección económica sobre el bien o servicio o aspectos de índole social, entre otros. Sin embargo, por efectos de la estructura misma del impuesto en cadena económica con alcance sobre cada una de las etapas de producción, distribución y comercialización, y la incidencia del gravamen en proporción al valor agregado

${ }^{6} \mathrm{Al}$ respecto artículo 420 del Estatuto Tributario Nacional. 
que es incorporado en cada una de ellas, los hechos exonerados del IVA cobran un vital análisis en su concepción, en la medida en que el IVA es un impuesto al consumo, este puede generar distorsiones económicas, alteración sobre los precios en cada una de las etapas o inclusive incidir en los factores de producción. Por ello, se abordan algunas consideraciones adicionales en relación con las exoneraciones perfecta e imperfecta y la naturaleza misma de estas desgravaciones, con el fin de dejar presente las más relevantes consecuencias de su calificación como tales.

Este análisis, en relación con el IVA y los efectos de neutralidad e incidencia en el precio, debe abordarse a partir de la distinción entre el actor tributario (responsable) y el contribuyente (consumidor). A pesar de que para nuestra legislación estos dos conceptos pueden ser considerados sinónimos ${ }^{7}$, es necesario advertir que para comprender el sistema son realmente actores distintos, pues mientras el responsable es el deudor legal por consideración de la ley, el contribuyente es sobre quien recae económicamente el gravamen (consumidor). Así, en la doctrina han sido denominados sujeto pasivo jurídico y sujeto pasivo económico ${ }^{8}$.

De tal manera, desde la óptica del deudor tributario el impuesto puede ser considerado neutro por la función eminentemente instrumental que le compete, fruto de la cual repercute a quien le siga en la cadena de producción y circulación de bienes o prestación de servicios y resta del impuesto generado los que a su turno le hayan sido repercutidos. Pero en lo que atañe al consumidor final, verdadero contribuyente o incidido con el impuesto, el IVA puede obrar como factor disuasivo para las decisiones de consumo o de inversión.

Es por ello que en consideración a la reacción que un impuesto genere en los contribuyentes, se hace referencia a los tributos con mayor o menor tendencia a los efectos "neutros", como expone Duverger (1980,p. 106), es neutro cuando no tiene por objeto ejercer una presión sobre los contribuyentes para incitarlos a una acción o a una abstención cualquiera.

En conclusión, la incidencia que sirve de referencia a la distinción, no es la que efectivamente se presenta desde el punto de vista económico, sino la que pretende el legislador al regular el impuesto. En el impuesto directo no hay derecho de repercusión del tributo ni las normas regulan en forma alguna las condiciones o características en que procede, mientras que en el impuesto indirecto, sí hay derecho de repercusión y las normas jurídicas regulan las condiciones y mecanismos en que opera, aunque a pesar de ello, no obstante, la teórica repercusión del tributo en una persona diferente, en algunas ocasiones se pueden tornar de manera plena o simplemente parcial.

\section{A. La exoneración perfecta, bienes y servicios exentos - el régimen de tasa cero}

La exoneración perfecta del régimen de IVA, en Colombia llamada "exención", se concibe como un hecho que si bien está incorporado en el régimen del impuesto sobre las ventas, no materializa el efecto principal

${ }^{7}$ Ver artículo 4. ${ }^{\circ}$ del Estatuto Tributario Nacional.

${ }^{8}$ Ver Concepto Unificado de IVA 001 de 2003. Dirección de Impuestos y Aduanas Nacionales DIAN-. Descriptores: Obligación Tributaria Sustancial - Elementos. p. 2. 
de la obligación tributaria (pagar el tributo), esto es debido a que en la naturaleza de pluricausación, el gravamen que se concibe sobre el bien o el servicio responderá a tasa cero o tarifa cero, consecuencia de la cual existe obligación del responsable de liquidar el impuesto y con base en el método de impuesto contra impuesto, los IVA relacionados a dicho bien o servicio exento le otorgan el derecho a descuento sobre el impuesto liquidado a tasa cero. Además, a diferencia de los hechos meramente gravados, donde existe de igual manera la posibilidad de que se descuenten del impuesto generado en tarifa general o diferencial impuestos conforme al método de impuesto contra impuesto, en el régimen de tasa cero no se materializa el efecto principal del tributo (generar valor de pago), simplemente la liquidación del impuesto arrojará un valor negativo de pago, es decir, un saldo a favor permanente del responsable, el cual nunca podría ser aplicado, y en razón de ello es el Estado quien está llamado a intervenir para generar la neutralidad esperada sobre el consumo, que en ningún momento puede perderse de vista como el objeto principal del impuesto.

Sobre este asunto, es importante traer a colación algunas líneas de suma importancia en relación con el sistema del Impuesto sobre el Valor Agregado, al respecto Plazas (2015) señala

El régimen de "tasa cero" (Zero Rated), como su nombre lo indica, parte de la base de considerar que los bienes materia del beneficio están gravados pero con tarifa cero. En términos simples, en virtud de este sistema el impuesto generado por la operación de venta de los bienes de que se trate, por parte del productor, equivale a cero (-0-), resultado de aplicar la tarifa
(-0-) a la base "gravable". Y como la operación queda cobijada por el ordenamiento por estar sometida al impuesto aunque con tarifa (-0-), quien la realiza es titular de los derechos y las obligaciones previstas en las normas del IVA como tal, quien debe presentar declaración tributaria y tiene la facultad de descontar los impuestos repercutidos. En definitiva, dado que el impuesto generado es cero (-0-), sus declaraciones tributarias, en lo que atañe a las operaciones exentas, arrojan saldo a favor y No a cargo. La devolución de ese saldo favor, por parte del Estado, es el resultado concreto del régimen de "tasa cero" (p. 377).

En dicho sentido es importante reiterar que el IVA es un tributo indirecto, y en tal virtud, las exenciones previstas en la ley favorecen al consumidor y no al deudor legal, motivo por el cual es claro que los efectos sobre el responsable o no responsable en el caso de los excluidos, tales como el derecho a descontar o no descontar impuestos, son la consecuencia jurídica de la aplicación del régimen en su estructura en la modalidad de valor agregado, y no por ello se puede confundir que lo accesorio del régimen, como puede ser el derecho a descuento, termine por incorporarse como la diferencia principal entre exención o exclusión, pues esto desconocería ampliamente que la esencia del régimen responde al objeto consumo y, en esa medida, la clasificación se realiza en función del consumo y no en función de los efectos para el responsable o no responsable, de quien vale recordar es un intermediario en la consecución del gravamen.

Esta consideración es de vital importancia, toda vez que si se llegara a considerar en tal sentido, como infortunadamente algunos autores la realizan, estaríamos frente a 
elementos que podrían llevar en el análisis del régimen a infortunadas interpretaciones que pueden dar lugar a error. De ello, valdría la pena traer a colación un ejemplo básico, y es que si lo principal del régimen exento fuera el derecho a descuento o a contrario sensu no dar derecho descuento para el caso del excluido, sin atender a la naturaleza y estructura del régimen en pluricausación y que su objeto es el consumo, los bienes exentos sin observar su función en la cadena económica otorgarían simplemente "derecho a descuento". Sin embargo, esto no es cierto y, en tal sentido, los bienes exentos, aunque son calificados como tales por la ley, en etapas de comercialización no dan derecho a descuento (Estatuto Tributario, art. 439-440). Obsérvese así que el consumo es el actor principal de la cadena del IVA y la calificación por el legislador de exento encuentra su importancia en el consumo, lo relacionado al responsable son efectos o medidas que se toman para generar neutralidad en el impuesto.

Claro esto, es necesario para el impuesto sobre las ventas, por su estructura de pluricausación, regresar a los factores de neutralidad y de incidencia en el precio antes referidos, puesto que al ser el objeto $e l$ consumo, este puede verse incidido por los elementos y eventos intervinientes de la cadena, los cuales son efectos que son trasladados de un agente económico de la cadena al siguiente agente económico o eslabón, incidiendo en factores como el precio o el consumo, como a su vez, también, pueden ser retrotrasladados al agente económico precedente en la cadena, vía cantidad o afectándose el volumen de producción.

Para una mejor compresión se ofrece la siguiente figura que muestra las dinámicas de este fenómeno.

\section{Figura 3. Fenómeno de traslación o retrotraslación}

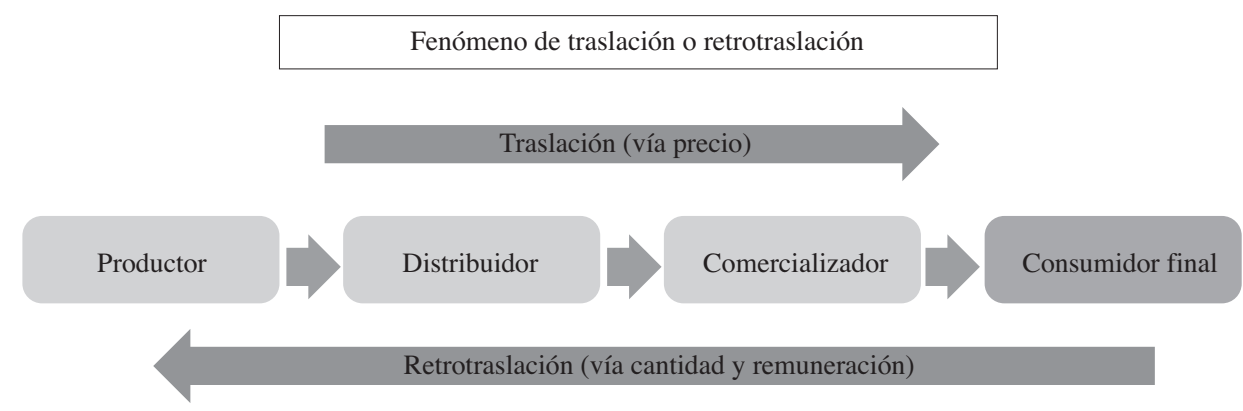

Fuente: elaboración propia, 2015.

En este mismo sentido, expone Plazas (2015, p. 5) que la traslación puede presentarse hacia adelante o hacia atrás en el momento económico. En el primer caso, afecta aspectos tales como el volumen de producción o el precio. En el segundo, afecta la cantidad utilizada de factores y su remuneración.
Estos son los fenómenos de traslación y retrotraslación, que se originan como efecto económico de la cadena del IVA.

Así, del análisis particular del bien exento y de su función de cadena económica y su factor de incidencia, ha sido ya inicialmente establecido que la exención se predica sobre 
el bien o servicio y en tal sentido la exoneración se logra sobre el consumo, llegando el producto al consumidor libre de gravamen, porque no habrá incidencia esperada en el precio del consumidor final y, a su vez, cualquier valor por IVA que pague será devuelto por el Estado. Sin embargo, calificar por parte del legislador un determinado bien o servicio como exento exige por parte del Estado un importante factor de eficiencia administrativa para que funcione de la manera esperada o correctamente, esto sumado a un pormenorizado control, lo que genera que a pesar de que el IVA encuentre en su propia estructura un autocontrol del impuesto, a su vez también se ve amenazado por prácticas de fraude que inciden en índices de evasión, que si bien son inferiores a la del impuesto de renta, resultan ser relativamente altos (Piza, 2015, p. 33).

$\mathrm{Al}$ respecto, se ilustra el efecto en cadena que se incorpora con la calificación de exento.

\section{Figura 4. Exentos (exoneración perfecta)}

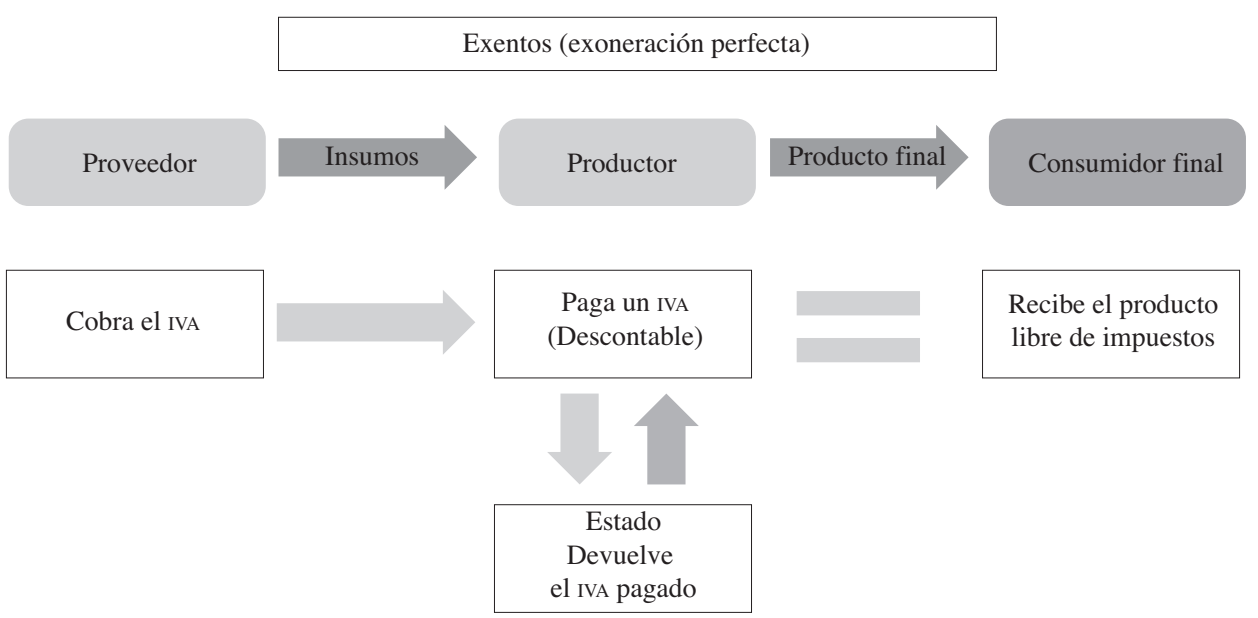

Fuente: elaboración propia, 2015.

A su vez, en este escenario es necesario aludir a que si bien el factor esperado de incidencia de un bien exento en la cadena debe ser neutro, de la manera que no se afecte su consumo y se proteja la cadena económica, la capacidad administrativa para responder ante tal sistema puede en muchas ocasiones ser ínfima, generando afectaciones de capital de trabajo sobre quienes son responsables y hacen parte de la cadena en dichos bienes o servicios, al punto que por incidencia en sus flujos de efectivo, tales como tener que asumir el pago de los impuestos, mientras se surten los procedimientos de devoluciones, genera que el productor termine por trasladar vía precio, en proporción, el sacrificio de flujo de efectivo que debe realizar por el sistema, para no verse afectado en el desarrollo de su actividad.

Finalmente, atendiendo que la legislación colombiana señala algunos hechos exentos ${ }^{9}$ del impuesto, consagrados principalmente por los artículos 477, 478 y 481 del Estatuto Tributario Nacional, como listados taxativos, así como algunas normas complementarias, se citan en lo pertinente como ejemplo 
algunos servicios, llamando la atención su puntual y limitada desgravación legal:

1. Los servicios intermedios de la producción de bienes que se presten a las sociedades de comercialización internacional, siempre que los bienes finales sean efectivamente exportados (Lit. b del artículo 481 del Estatuto Tributario).

2. El servicio de conexión y acceso a internet de suscriptores residenciales de los estratos 1 y 2 (Lit. h del artículo 481 del Estatuto Tributario).

3. Los servicios que se exporten (Lit. c y d del artículo 481 del Estatuto Tributario).

4. Los servicios de educación en algunos casos - Instituciones estatales u oficiales de educación superior- (Ley 30, 1992, art. 92).

En contraposición, se comentará a continuación acerca de la exoneración imperfecta.

\section{B. La exoneración imperfecta, bienes y servicios excluidos}

La exclusión fue una medida que se adoptó por el régimen colombiano, en su mayor parte por la Ley 50 de 1984 y la Ley 49 de 1990, pasando lo que hasta ese momento se consideraban como bienes exentos a bienes excluidos, en tal sentido, y como ya se ha explicado, las exclusiones han funcionado como una delimitación negativa del hecho generador del impuesto, sin embargo, este sistema a pesar de intentar eliminar la realización del hecho imponible, genera a partir de las características económicas propias del sistema, efectos en los precios y el consumo, como a su vez distorsiones en los elementos de volumen de producción y remuneración, pues a diferencia de la exención, donde no se abstraen los bienes o servicios del régimen de IVA, la calificación de excluido si tiene como consecuencia, abstraer del régimen el bien o el servicio determinado y, por ello, finalizar la cadena de pluricausación hasta allí incorporada, resultado del cual queda fuera del régimen y, por ello, sin el alcance de los efectos de este, entre ellos permitirle al agente económico liquidar impuesto y descontar los impuestos pagados, pues se constituye en un no responsable del impuesto.

Empero, al ser quebrada la cadena, en la acepción de pluricausación, pues la cadena económica llega, sin embargo, hasta al consumidor final, este sistema genera unas consecuencias económicas para quienes intervienen como agentes económicos en la cadena productiva o de prestación, tales como que si no pueden liquidar impuesto no habrá lugar al descuento de los IVA que le fueron necesarios sufragar para lograr producir el bien o prestar el servicio, y en tal medida, este ahora no responsable tendrá que asumir el valor pagado como un costo o gasto en su actividad, lo que deviene en imperfección del sistema.

\footnotetext{
${ }^{9}$ A pesar de lo neutral que se pueda llegar a considerar la exención como exoneración perfecta en régimen de "tasa cero", en el derecho supranacional dicho régimen ha sido llamado a limitarse a operaciones de comercio internacional únicamente. Al respecto el artículo 20 de la Decisión 599 de la Comunidad Andina de Naciones- CAN-.
} 
Ahora, si bien las no sujeciones están inspiradas en imprimir al impuesto un presunto sesgo social, en cuanto se excluyen generalmente del impuesto los bienes y servicios básicos, como algunos alimentos o el transporte, salud, vivienda, educación, entre otros, no podrá perderse de vista que estos productos básicos o servicios encontraran una afectación en su precio derivada de quién presta el servicio o vende el bien, no querrá asumir el costo que el Estado intenta que asuma para no trasladarlo al consumidor final, razón por la cual intentará trasladarlo vía precio para que su utilidad no se vea afectada.

Así las cosas, se puede concluir en relación con la exclusión, desde la estructura misma del impuesto y del objeto del consumo, en juicios de Plazas (2015, p. 360) que este tipo de exoneración sobreviene en antitécnica, injusta, así como lesiva del comercio internacional. De manera general, es antitécnico, porque desconoce la estructura y características de recaudo del impuesto, generando efectos extratributarios; injusta porque los productos de primera necesidad deberían responder a una exoneración perfecta y no imperfecta, con afectación vía precio; y lesivo del comercio internacional, porque se deja en desventaja a los productores nacionales frente a los importadores de productos, en tanto el importador bajo el principio que tiene el impuesto de imposición en el destino no tendrá el producto con IVA incorporado, ni tendrá que liquidarlo en su operación de importación, pero el productor colombiano tendrá que incorporarlo vía precio, pues su cadena productiva lo obligará a hacerlo.

Conforme a estos juicios, se puede destacar que esta calidad adicionalmente puede recaer en contrariedad de la normatividad supranacional, toda vez que existe prohibición expresa de calificar, pero además de crear exclusiones adicionales a las preexistentes a partir de las disposiciones de armonización de la CAN (Decisión CAN 599, 2004, arts. 23 a 25), con base en la cual a Colombia se asiste obligación de cumplimiento como miembro de dicho organismo (Sentencia C-227 de 1999).

En consecuencia, las exclusiones del régimen mantienen algunas consecuencias económicas sobre los precios en la medida que el valor es llevado hacia adelante como fenómeno de traslación, sin embargo, es de anotar adicionalmente que por características propias de la economía no siempre es así, puesto que pueden incidir factores adicionales como la elasticidad de la oferta y la demanda o los regímenes de control de precios. Esto es que si bien, se tiene por el no responsable unos pagos por impuestos que no se lograran como descontables, las características propias del bien o servicio no le permitirá incorporarlas vía precio, de lo contrario, la afectación podría ser aún mayor, como, por ejemplo, que el consumidor adquiera un bien o servicio diferente (sustituto), motivo por el cual la consecuencia no será trasladada hacia adelante, pues existiendo este distorsionante en la producción, el no responsable tendrá que incidir forzosamente su utilidad, o repercutir en menor producción o menor remuneración al eslabón precedente (retrotraslación), al convertirse sus recursos en más limitados.

Al respecto, se ilustra el efecto en cadena que se incorpora con la calificación de excluido. 


\section{Figura 5. "Excluidos" (exoneración imperfecta)}

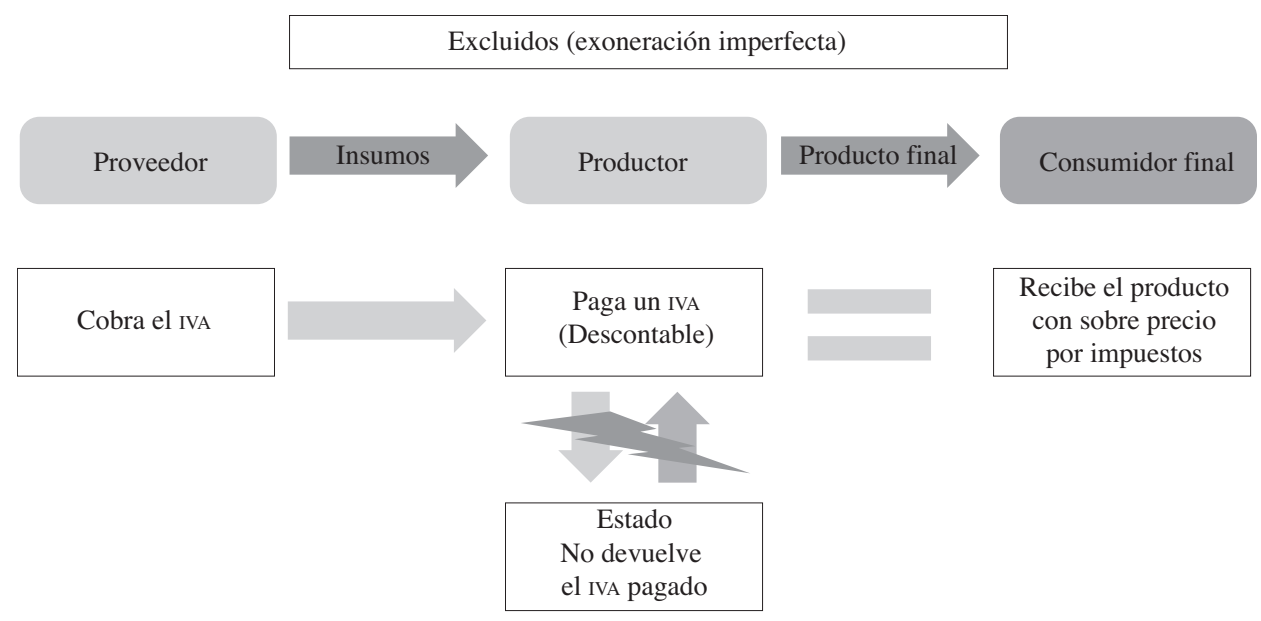

Fuente: elaboración propia, 2015.

Ahora bien, este tipo de elementos permiten considerar que la exoneración por exclusión responde además, en sus consecuencias, a una "zona gris" en el régimen del IVA, pues si bien el consumo aparentemente se libra del gravamen de manera formal, porque no es cobrado como tal, no lo es así desde el escenario económico, pues se traslada vía precio, inclusive pudiéndose agudizar su impacto económico cuando en el comercio se alarga la cadena, o con afectación en la producción o el consumo de ciertos bienes o servicios. Contrario a ello, es la exoneración por exención, la cual logra librar el consumo del gravamen tanto de manera formal como económicamente, es decir, en incidencia de precio o producción.

De tal manera, cabe destacar que las exclusiones en dicho sentido del consumo, deberán responder a un listado muy limitado en el régimen de IVA, en tanto que desde un punto de vista práctico presentan una mayor incidencia que las exenciones, sin embargo, no es así, lo que se traduce en el reconocimiento estatal de no lograr solventar la participación eficiente que demanda la estructura del IVA, para entregar la más adecuada y perfecta cadena del sistema.

Finalmente, a pesar de los inconvenientes y las distorsionantes características de las exclusiones frente al régimen de IVA, el cual grava de manera objetiva bienes o servicios, es de agregar que no solo se incorpora el factor distorsionante de quiebre a la cadena de pluricausación del IVA, sino que además existe en la legislación exclusiones subjetivas, es decir, que a pesar de que la naturaleza del impuesto es indirecta, y en poco o en nada consulta las características del individuo, algunas de las exclusiones se han concebido en relación con las características del sujeto pasivo. Así las cosas, existen dos modalidades de exclusión, en forma objetiva y en forma subjetiva, para lo cual cabe hacer la mención de algunos ejemplos en relación con ellas:

\section{a) Bienes excluidos en forma objetiva}

Forman parte de este grupo los bienes, cuya exoneración obedece a su naturaleza 
misma, independientemente del destino final, entre otros los contemplados por el artículo 424 del Estatuto Tributario Nacional, a manera de ejemplo:

- Animales vivos de la especie porcina.

- Animales vivos de las especies ovina o caprina.

- Peces vivos, excepto los peces ornamentales de algunas posiciones arancelarias

- Miel natural.

- Café en grano sin tostar.

- Cáscara y cascarilla de café.

\section{b) Bienes excluidos en virtud de su destina- ción (en forma subjetiva)}

Aun cuando desde el punto de vista de la incidencia pretendida por el legislador, la condición de deudor legal la ostenta el vendedor y no el comprador, y en tal sentido no es natural al régimen establecer exclusiones en razón de su destinación, entre otros, a manera de ejemplo se pueden destacar los señalados por el artículo 424 del Estatuto Tributario:

- Las materias primas químicas con destino a la producción de algunos medicamentos.

- El petróleo crudo destinado a su refinación.

- Los equipos y elementos nacionales o importados que se destinen a la construcción, instalación, montaje y operación de sistemas de control y monitoreo, necesarios para el cumplimiento de las disposiciones, regulaciones y estándares ambientales vigentes.

- Los vehículos automotores destinados al transporte público de pasajeros, destinados solo a reposición.

A favor de la modalidad de exclusión subjetiva, a pesar de que desde la estructura del impuesto resulta inadecuada, habrá que reconocer que es necesario en ocasiones acudir a la exoneración por el destino, en particular cuando el legislador procura por incentivar ciertos consumos por motivos de interés económico, social o cultural. En esos casos, en palabras de Plazas (2015, p. 373), por la inconveniencia de exonerar objetivamente los bienes de manera general, no hay alternativa distinta a la de estructurar la exoneración en función del destino, aunque ello no deja de lado que el escenario perfecto se atendería a través de la exención.

Ahora bien, expuestos los efectos de cadena que conllevan cada una de las características económicas del régimen del impuesto sobre las ventas en Colombia, partiendo de la estructura jurídica y hechas las consideraciones desde el punto de vista dogmático y conceptual, se comentará finalmente la estructura natural de incidencia a que responde el régimen de IVA vía cadena de producción y en la cual no solo intervienen bienes, sino que se incorporan servicios, aquellos que son necesarios para el consumo de dichos bienes.

\section{Consideraciones de la incidencia económica en cadena de la relación de servicios a bienes en dirección del consumo de bienes}

Con base en las consideraciones expuestas, podremos finalmente destacar la relación que guardan algunos servicios a bienes. Estas relaciones nacen desde la concepción misma del gravamen en modalidad plurifásica y en función del bien objeto de consumo de la cadena económica que le precede en su producción.

Para colocar en contexto la relación de servicios a bienes en dirección del consumo 
de bienes, es decir, distinta de la acepción de incorporación de bienes a prestación de servicios donde los servicios son el objeto de consumo ${ }^{10}$, se debe precisar que existen servicios que son prestados en cadenas productivas de bienes y, en ese sentido, guardan una estrecha relación a un bien resultante. A manera de ejemplo, y trayendo a colación un contexto de servicios para la salud humana, debe resaltarse que bienes, servicios y servicios relacionados a bienes son tres elementos distintos. Como ya se ha dicho, en la medida que estos elementos de objetividad sean totalmente claros en la aplicación de la norma, no habrá lugar a extensiones o interpretaciones erradas que puedan afectar la correcta aplicación del régimen.

Para el caso de los servicios médicos y los medicamentos, por ejemplo, con el fin de entender la relación de servicios a bienes, se puede agregar un tercer elemento, los servicios prestados para la producción de los medicamentos. Así las cosas, los servicios son los servicios médicos, los bienes, los medicamentos y los servicios relacionados a bienes, los servicios necesarios para la producción de medicamentos. En relación con los servicios que pueden intervenir en la cadena, se puede destacar que mientras de los servicios necesarios para la producción de medicamentos se obtienen medicamentos, de los servicios médicos no resulta ningún bien corporal y no existe ningún proceso productivo, es decir, es un servicio independiente y en términos de la definición reglamentaria de servicios ${ }^{11}$ obedece a una obligación de hacer.
En tal sentido, se denota que en relación con los servicios en el IVA, se tienen a aquellos de los cuales existe una relación a bienes, así como otros que no guardan relación alguna a estos, sin embargo, ambos tipos dentro de la definición normativa de servicios y que se concretan en una obligación de hacer.

Para ilustrar la relación entre servicios y bienes, se puede contemplar, a continuación.

\section{Figura 6. Servicios relacionados a bienes}

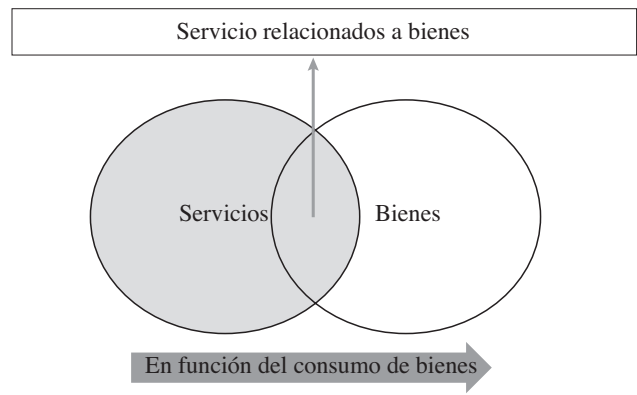

Fuente: elaboración propia, 2015.

Clara así la diferencia en relación con los ciclos económicos, se concluye que es distinta la dependencia de un servicio que se preste dentro de un proceso productivo de un bien y otra la prestación de un servicio autónomo, del cual no se obtiene ningún bien. De igual manera que existen servicios que no guardan ninguna relación a bienes (por ejemplo, los honorarios en su generalidad) y bienes que nada tienen que ver con los servicios (regularmente los primarios), en todo caso hay bienes que dependen en su proceso productivo de las obligaciones de hacer (servicios) para que puedan producirse y tenerse en condiciones de utilización o terminación.

\footnotetext{
${ }^{10}$ A manera ejemplo véase la regla del literal c del artículo 421 del Estatuto Tributario.

${ }^{11}$ Artículo 1. ${ }^{\circ}$ del Decreto 1372 de 1992.
} 
Motivo por el cual, el proceso económico y el impuesto sobre las ventas debe responder a esta natural relación de "servicio-bien", y en nuestra legislación se ha concebido como la regla general el denominado servicio intermedio de la producción (Estatuto Tributario, parágrafo art. 476), importante elemento que se contempló por el legislador desde la concepción misma del impuesto al gravar bienes, relación económica que trasciende a la aplicación práctica dada la incidencia económica del impuesto en cadena.

Regresando al sentido de la objetividad del impuesto, y con el fin de ilustrar su aplicación, se obtiene entonces que los servicios médicos son excluidos, esto en virtud del numeral $1 .^{\circ}$ del artículo 476 del Estatuto Tributario, por su parte los medicamentos son excluidos, pero en virtud del artículo 424 del mismo ordenamiento, y finalmente en efecto de cadena y reconocimiento necesario de la aplicación de pluricausación, los servicios prestados en la producción de medicamentos son excluidos, pero en virtud el parágrafo del artículo 476 del Estatuto Tributario, por guardar relación el servicio de manera directa a un bien determinado.

Por lo expuesto, se deben destacar entonces dos conclusiones, la primera que el IVA como gravamen objetivo identifica claramente el hecho factico y grava en función de este hecho (consumo) sin distinción a su contexto, destinación o características del individuo, a menos que sean incorporados estos matices expresamente por el legislador y, en segundo lugar, que si bien en principio se ha entendido que los servicios responden a listados taxativos de gravados a tarifa diferencial, exentos y excluidos, esta afirmación no es del todo acertada en la medida de la relación que guardan algunos servicios a bienes, pues a partir de dicha relación se pueden originar servicios que tenga la calidad de exentos, excluidos o gravados en tarifa general o diferencial, en tantos bienes calificados existan o puedan existir y se hagan parte los servicios de sus cadenas productivas.

Finalmente, en reflexión de la estructura misma del impuesto sobre las ventas en Colombia, es dable destacar que el IVA siendo absolutamente estructural en las finanzas estatales debido a su alto y pronto poder recaudatorio, se contempla además como un factor determinante en la economía, motivo por el cual su incidencia debe analizarse no solamente desde la estructura misma del sistema tributario en lo jurídico, sino en consonancia con los efectos económicos para escenarios de producción, precios, inversión y consumo, conforme a los efectos de traslación y retro traslación, razón que origina desde la objetividad misma que atañe a la naturaleza del impuesto, que las decisiones de política fiscal en relación con el IVA deban procurar por una valiosa consideración de equilibrio entre lo económico y lo jurídico para su aplicación. 


\section{Referencias}

\section{Normatividad}

Constitución política de Colombia. (1991). Bogotá: Legis.

Ley 6 de 1992. (30 de junio de 1992). Colombia.

Ley 50 de 1984. (27 de diciembre de 1984). Colombia.

Ley 49 de 1990. (28 de diciembre de 1984). Colombia.

Decreto 1372 de 1992. (20 de agosto de 1992). Colombia.

Decreto Legislativo 2821 de 1974. (20 de diciembre de 1974). Colombia.

Decisión 599. Armonización de aspectos sustanciales y procedimentales de los impuestos tipo valor agregado.

Comisión de la Comunidad Andina-CAN- del 12 de julio de 2004.

Decisión 600. Armonización de los impuestos tipo selectivo al consumo. Comisión de la Comunidad Andina -CAN- del 12 de julio de 2004.

Decisión 635. Modificación de las Decisiones 599 y 600 relativas a la armonización de aspectos sustanciales y procedimentales de los impuestos tipo valor agregado y armonización de los impuestos tipo selectivo al consumo. Comisión de la Comunidad Andina -CAN- del 19 de julio de 2006.

Estatuto Tributario Nacional. (2015). Bogotá: Nueva Legislación.

\section{Obras académicas}

Castañeda, J. (2010). Aplicación del IVA en Colombia. Bogotá: Estudios Fiscales.

Duverger, M. (1980). Hacienda pública. Barcelona: Bosch Casa Editorial.

Martin, J. (2005). Curso de derecho financiero y tributario. Madrid.

Piza, J. (Ed.). (2015). Analisis del hecho generador del IVA en el ordenamiento juridico colombiano. Bogotá: Universidad Externado de Colombia.

Plazas, M. (1993). El IVA en los servicios. Bogotá: Temis.

Plazas, M. (1998). El impuesto sobre el valor agregado IVA. Bogotá: Temis.

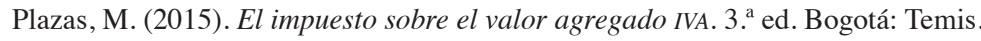

Ramírez. (1994). El impuesto sobre el valor añadido. Madrid: Civitas.

\section{Doctrina oficial}

Dirección de Impuestos y Aduanas Nacionales -DIAN-. (19 de junio de 2003). Concepto unificado de IVA número 001. Descriptores: servicios intermedios de la produccion.

Dirección de Impuestos y Aduanas Nacionales -DIAN-. (5 de octubre de 2005). Concepto tributario número 071920. Servicio de control de calidad en fabricación de medicamentos. 
Consideraciones conceptuales de incidencia económica y de estructura jurídica del impuesto...

Dirección de Impuestos y Aduanas Nacionales -DIAN-. (4 de diciembre de 2006). Oficio tributario número 102048. Servicio de auditoria médica.

Dirección de Impuestos y Aduanas Nacionales -DIAN-. (24 de noviembre de 2008). Oficio tributario número 6063. Servicios medicos y de odontologia excluidos. 